\title{
Clinical and epidemiological profile of patients undergoing total hip arthroplasty
}

Liz Araujo Wolfovitch ${ }^{1 *}$, Fernanda Rezende Campos Falcao ${ }^{1}$, Bruno Anderson Gomes Dias ${ }^{1}$, David Sadigursky ${ }^{2}$, Gustavo Castro De Queiroz $^{1}$ and Magda Leao Pinheiro ${ }^{1}$

${ }^{1}$ Faculdade de Tecnologia e Ciência, Brasil

${ }^{2}$ Faculdade de Tecnologia e Ciência e Clínica de Ortopedia e Traumatologia, Brasil

\begin{abstract}
Objective: Describe the clinical and epidemiological profile of patients undergoing total hip arthroplasty by analyzing the correlations between gender and indication of surgery and postoperative complications.

Methods: Cross-sectional study in retrospective approach of the medical records of patients undergoing total hip arthroplasty in a private Hospital in Salvador, Bahia in 2013 and 2014.

Results: $66,3 \%$ of patients are women, aged between 71 and 80 years (31,2\%), systemic arterial hypertension patients (63, 9\%), whose major indication occurred coxarthrosis $(48,2 \%)$ followed by hip fracture (39, 8\%); mostly by falling from height $(66,7 \%)$. Among the complications, anemia prevailed (53\%) and death occurred in only 2, 4\%. By correlating sex with indication of arthroplasty, hip fracture was only statistically significant in women ( $\mathrm{p}=0.004)$; in complications, anemia ( $\mathrm{p}=0.024)$ and urinary tract infection $(\mathrm{p}=0.025)$ had statistically significance in women and in men genitourinary changes $(\mathrm{p}<0.001)$.

Conclusions: Patients undergoing hip arthroplasty are elderly, female, hypertensive, most of whose procedures ran from coxarthrosis or hip fracture. Among the complications prevailed anemia, genitourinary, cardiovascular and digestive changes. Hip fracture, anemia and urinary tract infection are significantly more prevalent in females, while the genitourinary changes are significant in males.
\end{abstract}

Levels of evidence: III.

\section{Introduction}

Total hip prosthesis surgery, or arthroplasty, is a hip joint replacement procedure aimed at restoring a function of the hip joint, relieving pain and improving functional capacity, thereby improving the quality of life of patients suffering from pathologies that involve them [1].

In the past, patients aged 60 yo. up to 75 yo. were considered the best candidates for a hip arthroplasty. But nowadays, this trend has been modified and older patients were included. Most of those patients now have a greater number of comorbidities, as well as younger patients, in whom the implants can be exposed to great stress during life-time. Many of the candidates, for total hip arthroplasty, are women, elderly, whom presents cardiopathy, nephropathies, diabetics, obstructive vascular disease, senile dementia, Parkinson's disease, pneumopathies (COPD), etc.

Its main indication is the presence of severe pain accompanied by functional limitation [2]. HTA (hip total arthroplasty) is the surgical procedure widely used for the treatment of conditions of the hip joint, that could be included degenerative, inflammatory or traumatic issues, but mostly for the treatment of hip osteoarthritis. The World Health Organization estimates that $10 \%$ of the world's population, over 60 years of age, with osteoarthritis, $80 \%$ of the population has movement restriction and $25 \%$ have functional limitations in day-to-day activities. This surgery may also be indicated in other situations, such as femoral fracture, common in the elderly, as well as in the treatment of rheumatoid arthritis and avascular necrosis [3].
It is worth mentioning that the prevalence of HTA complications has decreased over the years, with consequent increase in its longevity, due to advances in the design of implants, materials, surgical technique and anesthetic. This surgical procedure is subject to specific complications, as well as complications inherent of any surgery. Nerve injury, bleeding, and thromboembolism may occur soon after surgery. Loosening, failure of the components and osteolysis are complications that can occur years later after the initial procedure. Infections, dislocations and femoral fractures may occur at any time after the surgery [4].

It is known that total hip arthroplasty is a complex surgical procedure involving a multidisciplinary team. Knowing more about the common aspects of HTA will help orthopedists and the surgical team better understand the epidemiology of their patients, facilitating the adequacy of their ducts to prevent the occurrence or severity of complications.

The aim of this article is to describe the clinical and epidemiological profile of patients submitted to total hip arthroplasty, also analyzing

Correspondence to: Liz Araujo Wolfovitch, Faculdade de Tecnologia e Ciência, Doutor Rubem Chaves street, number 10, Jardim Apipema, Salvador-BA, Brasil Zip code: 40155-330. Tel: +55(71) 982589899; E-mail: lica_wolf@hotmail.com

Key words: orthopedics, hip arthroplasty, health profile, postoperative complications Received: April 24, 2017; Accepted: May 29, 2017; Published: June 01, 2017 
the correlation between the sexes and an indication of the surgery, as well its complications.

\section{Methods}

The study is a cross-sectional study of patients submitted to total hip arthroplasty at a private hospital in Salvador, Bahia, from January 2013 to December 2014. The sample size was calculated with a $95 \%$ confidence level and error of 5\%, resulting in 84 patients. Thus, through ICD-10, a list of all patients submitted to total hip arthroplasty was generated in that period. Patient block randomization was performed, and the 84 patients were divided for each surgical group; 42 patients for each group, totaling 84 patients involved.

Inclusion criteria included patients submitted to total hip prosthesis, aged over 18 years, from January 2013 to December 2014; The exclusion criteria were: patients submitted to total hip arthroplasty who had incomplete medical records.

The data collection was performed retrospectively, through an electronic data of patients submitted to total hip arthroplasty, from January 2013 to December 2014. The data were tabulated in the Microsoft Excel program; And the data analysis was obtained by the SPSS program.

The variables of interest collected were: sex; age; Pre-existing comorbidities; death; Indication of total hip arthropathy; Use of cement; Operated side and postoperative complications. Postoperative complications were grouped into large groups to facilitate understanding. Variables were analyzed using descriptive statistics. The absolute and relative frequencies were used for nominal variables; And the numerical variables, discrete or continuous, were analyzed according to the central tendency (median and fashion) and the dispersion (standard deviation and quartiles). To evaluate the correlation between two variables, the Fisher or Chi-Square test was used; Being considered statistically significant when $\mathrm{p}<0.05$.

There are no conflicts of interest in this study.

\section{Results}

Among the 84 patients in the sample, only 83 were eligible for analysis. One patient was transferred after the surgery, the medical record was incomplete for analysis and, therefore, it was excluded.

Of the 83 charts analyzed, 55 patients were female (66.3\%) and 28 were male (33.7\%), age ranged from 33 to 95 years, with a mean of 66.77 years and median of 69 years (standard deviation of 15.73). Patients were predominantly aged between 71 and 80 years $(31.3 \%)$, being the lowest percentage presented by patients between 91 and 100 years (Table 1).

Table 2 shows the main comorbidities and pre-existing problems of patients submitted to total hip arthroplasty. Systemic arterial hypertension, dyslipidemia and diabetes were the most prevalent diseases, while smoking and alcoholism prevailed among living habits. In the surgical procedure 3 variables were analyzed: the side in which procedure was performed, cement use and indication of surgery. It was observed that total hip arthroplasty was performed on the right side in 50 patients $(60.2 \%)$, and in 33 patients on the left side $(39.8 \%)$, with cement being present in 31 patients $(37.3 \% \%)$. Coxarthrosis was the indication of the most prevalent total hip arthroplasty, followed by hip fracture (Table 3). It is noteworthy that, among the patients that presented fracture, as a cause of the indication of total hip arthroplasty, the majority was due to a fall from the self-height (66.7\%).
Table 1. Sociodemographic characteristics of patients undergoing total hip arthroplasty

\begin{tabular}{|c|c|c|}
\hline Variables & $\mathbf{n = x}$ & $\mathbf{\%}$ \\
\hline Gender & & \\
\hline Female & 55 & 66,3 \\
\hline Male & 28 & 33,7 \\
\hline & & \\
\hline Age & & 7,2 \\
\hline $31-40$ years & 6 & 9,6 \\
\hline $41-50$ years & 8 & 16,9 \\
\hline $51-60$ years & 14 & 18,1 \\
\hline $61-70$ years & 26 & 31,3 \\
\hline $71-80$ years & 12 & 14,5 \\
\hline $81-90$ years & 2 & 2,4 \\
\hline $91-100$ years & & \\
\hline & & \\
\hline
\end{tabular}

Table 2. Pre-existing problems of patients undergoing total hip arthroplasty

\begin{tabular}{|c|c|c|}
\hline Variables & $\mathbf{n}=\mathbf{x}$ & $\mathbf{\%}$ \\
\hline Comorbidities & & 63,9 \\
\hline $\begin{array}{c}\text { Systemic Arterial } \\
\text { Hypertension }\end{array}$ & 53 & 28,9 \\
\hline Diabetes & 24 & 20,5 \\
\hline Dyslipidemia & 17 & 7,2 \\
\hline Obesity & 6 & 6 \\
\hline Rheumatoid Arthritis & 5 & 7,2 \\
\hline Hypothyroidism & 6 & 16,9 \\
\hline Cardiopathy & 14 & \\
\hline & & 9,6 \\
\hline Life Habits & 8 & 7,2 \\
\hline Alcoholism & 6 & 1,2 \\
\hline Smoking & 1 & \\
\hline Use of illicit drugs & & \\
\hline & & \\
\hline
\end{tabular}

Table 3. Indications of total hip arthroplasty

\begin{tabular}{|c|c|c|}
\hline Variables & $\mathbf{n = x}$ & $\mathbf{\%}$ \\
\hline Primary Arthroplasty & & 48,2 \\
\hline Coxarthrosis & 40 & 39,8 \\
\hline Hip Fracture & 33 & 7,2 \\
\hline Aseptic Necrosis & 6 & \\
\hline $\begin{array}{c}\text { Review of previous } \\
\text { prosthesis }\end{array}$ & & \\
\hline Previous prosthesis release & 6 & 7,2 \\
\hline Previous prosthesis infection & 2 & 2,4 \\
\hline $\begin{array}{c}\text { Previous prosthesis } \\
\text { dislocation }\end{array}$ & 4 & 4,8 \\
\hline Hip Fracture & 22 & 66,7 \\
\hline Fall from own height & & \\
\hline
\end{tabular}

Table 4 shows the frequency of postoperative complications in patients. The most common complications after total hip arthroplasty were grouped into several physiological systems to facilitate understanding. Thus, anemia, alterations of the genitourinary system, cardiovascular alterations, digestive tract and urinary tract infection were the most prevalent.

When analyzing the correlation between sex and the indication of arthroplasty (table 5), we found that only hip fracture was statistically significant in women $(p=0.04)$. On the correlation between sex and postoperative complications, we found that anemia and urinary 
Table 4. Postoperative complications of patients undergoing total hip arthroplasty

\begin{tabular}{|c|c|c|}
\hline Variables & $\mathbf{n}=\mathbf{x}$ & $\mathbf{\%}$ \\
\hline & & 10,8 \\
\hline Urinary tract infection & 9 & 53 \\
\hline Anemia & 44 & 34,9 \\
\hline Cardiovascular disorders & 29 & 6 \\
\hline Respiratory system disorders & 5 & 27,7 \\
\hline Digestive system disorders & 23 & 43,4 \\
\hline Genito-urinary disorders & 36 & 8,4 \\
\hline Nervous system disorders & 7 & 3,6 \\
\hline Hematopoietic disorders & 3 & 8,4 \\
\hline Infection & 7 & 10,8 \\
\hline Hydroelectrolytic disorders & 9 & 2,4 \\
\hline Insomnia & 2 & 7,2 \\
\hline Skin alterations & 6 & 1,2 \\
\hline Extremities edema & 1 & 2,4 \\
\hline Pain & 2 & 7,2 \\
\hline Mechanical alterations & 6 & 2,4 \\
\hline Death & 2 & \\
\hline
\end{tabular}

Table 5. Association between sex and indication of total hip arthroplasty

\begin{tabular}{|c|c|c|c|c|c|}
\hline \multirow{3}{*}{ Variables } & \multicolumn{4}{|c|}{ Gender } & \multirow[b]{3}{*}{ p-value } \\
\hline & \multicolumn{2}{|c|}{ Female } & \multicolumn{2}{|c|}{ Male } & \\
\hline & $\mathbf{n}$ & $\%$ & $\mathbf{n}$ & $\%$ & \\
\hline Coxarthrosis & 23 & 57,5 & 17 & 42,5 & 0,103 \\
\hline Hip Fracture & 28 & 84,8 & 5 & 15,2 & 0,004 \\
\hline Aseptic Necrosis & 3 & 50 & 3 & 50 & 0,400 \\
\hline Prosthesis release & 4 & 66,7 & 2 & 33,3 & 1,000 \\
\hline $\begin{array}{l}\text { Previous } \\
\text { prostheus } \\
\text { infection }\end{array}$ & 1 & 50 & 1 & 50 & 1,000 \\
\hline $\begin{array}{c}\text { Previous } \\
\text { prosthesis } \\
\text { deslocation }\end{array}$ & 3 & 75 & 1 & 25 & 1,000 \\
\hline
\end{tabular}

tract infection were significant in women, whereas alterations in the genitourinary tract were statistically significant in men, as shown in table 6 .

\section{Discussion}

Goveia et al., [5] in Minas Gerais, Brazil, demonstrated similar epidemiological data: $60 \%$ of the patients submitted to hip arthroplasty were women, $63 \%$ were patients between the ages of 70 and 90 years (mean age 73 years) presenting diagnosis of fracture of the femoral neck secondary to the fall from self-height. On the other hand, Yoo et al. [6] also reported male prevalence (55.8\%), but younger: $46 \%$ were aged between $45-64$ years and $24.1 \%$ between $65-74$ years.

Among comorbidities, cardiovascular diseases were the most prevalent; Other studies confirm that cardiovascular disorders are the most prevalent, being present in $47 \%$ of patients; And that patients with heart failure are about 6 times more likely to develop a hip fracture [7]. This finding may be explained by the fact that there is an association between the risk factors of the third proximal fracture of the femur and cardiovascular disorders, with the advancing age; As well as by the diminution of the tolerance to the exercise; diabetes; arterial hypertension; Use of diuretics and reduction of vitamin D levels, in which these factors are directly related to the reduction of bone metabolism.

Among the pre-existing comorbidities, Lima and Barone [8] showed that $39.1 \%$ of patients had no relevant disease, $15.2 \%$ had rheumatoid arthritis, $10.8 \%$ had systemic arterial hypertension, $4.3 \%$ had diabetes mellitus, and $13 \%$ had a history of previous local surgery. On the other side, Piano et al. [9] point out that among the patients submitted to HTA, $9.2 \%$ had diabetes, $45.9 \%$ were hypertensive, $9.2 \%$ were cardiopathic, $1 \%$ had osteoporosis and $12.3 \%$ were smokers. Memtsoudis et al. [10], disaccording, demonstrated in their systematic review congestive that heart failure, liver diseases, diabetes, cancer, neurological diseases and cardiac valvulopathies are the most prevalent comorbidities in patients undergoing arthroplasty.

Regarding the indication of arthroplasties, Lima and Barone [8] likewise showed that the indications for arthroplasty were, in 50\% of the cases, for hip ostearthrosis, $13 \%$ of rheumatoid arthritis, $15.2 \%$ aseptic necrosis of the femoral head, $10.8 \%$ of spondylitis ankylosing disease, $4.3 \%$ sequela of femur fracture, $2.1 \%$ sequela of hip pioarthritis, epifisiolistesis and bilateral ortopelvis. Another study, conducted in São Paulo, SP, Brazil, demonstrate that osteoarthrosis prevailed in $92.4 \%$ of patients, followed by osteonecrosis and hip fracture, and osteoarthrosis in $2 \%$, and osteosynthesis failure 1 . Yoon et al., [6] in Korea, show that $59 \%$ of primary hip arthroplasties occurred due to osteonecrosis and $28 \%$ due to osteoarthritis.

In addition, in the current study, about $66.7 \%$ of cases of hip fracture resulted from falls from the self-height. Studies carried out in 2007 [11] have shown that about $80 \%$ and $94 \%$ of patients with fracture had the main trauma mechanism to fall. Goveia and coworkers [5] affirm in the same way that the main cause of hip fracture was femoral neck fracture, caused by a fall in height, in $92 \%$ of the situations. Decreased functional capacity, decreased ability to perform activities independently, as well as the influence of environmental conditions predispose to the occurrence of this aggravation, which increases the risk with advancing age [11].

Abbas et al. [12] found that only $16.9 \%$ of the patients had complications, $2.5 \%$ presented surgical site infection, $2.5 \%$ were urinary infection (UTI), $1 \%$ dislocation, $2 \%$ pulmonary alterations, $0.5 \%$ thrombosis and $0.5 \%$ acute myocardial infarction (AMI). On the other hand, Dorman et al., [13] in a study with patients over 75 years, reported that almost $75 \%$ of the patients presented complications, involving pneumonia, UTI, pulmonary embolism, AMI, confusion and constipation. Memtsoudis et al. [10], in their systematic review,

Table 6. Association between sex and the postoperative complications of patients submitted to total hip arthroplasty

\begin{tabular}{|c|c|c|c|c|c|}
\hline \multirow{3}{*}{ Variables } & \multicolumn{4}{|c|}{ Gender } & \multirow[b]{3}{*}{ p-value } \\
\hline & \multicolumn{2}{|c|}{ Female } & \multicolumn{2}{|c|}{ Male } & \\
\hline & $\mathbf{n}$ & $\%$ & n & $\%$ & \\
\hline Urinary tract infection & 9 & 100 & 0 & 0 & 0,025 \\
\hline Anemia & 34 & 77,3 & 10 & 22,7 & 0,024 \\
\hline Cardiovascular disorders & 19 & 65,5 & 10 & 34,5 & 0,916 \\
\hline $\begin{array}{c}\text { Respiratory system } \\
\text { disorders }\end{array}$ & 4 & 80 & 1 & 20 & 0,658 \\
\hline Digestive system disorders & 16 & 69,6 & 7 & 30,4 & 0,694 \\
\hline Genito-urinary disorders & 16 & 44,4 & 20 & 55,6 & $<0,001$ \\
\hline Nervous system disorders & 5 & 71,4 & 2 & 28,6 & 1,000 \\
\hline Infection & 3 & 42,9 & 4 & 57,1 & 0,219 \\
\hline Hematopoietic disorders & 1 & 33,3 & 2 & 66,7 & 0.262 \\
\hline $\begin{array}{l}\text { Hydroelectrolytic } \\
\text { disorders }\end{array}$ & 8 & 88,9 & 1 & 11,1 & 0,261 \\
\hline Insonmia & 1 & 50 & 1 & 50 & 1,000 \\
\hline Skin alterations & 3 & 50 & 3 & 50 & 0,400 \\
\hline Extremities alterations & 1 & 100 & 0 & 0 & 1,000 \\
\hline Pain & 2 & 100 & 0 & 0 & 0,547 \\
\hline Mechanical alterations & 5 & 83,3 & 1 & 16,7 & 0,658 \\
\hline
\end{tabular}


reported cardiac, pulmonary, AMI and pneumonia complications, as more prevalent post-arthroplasty complications.

When analyzing the incidence of infection in the patients of this study, we noticed that $10.8 \%$ presented urinary infection and $8.4 \%$ had other types of infection. A retrospective cohort study demonstred that the prevalence rate of infection in total hip arthroplasty was $2.8 \%$ of the cases, and that among all patients, who had infection, the majority were women, but without statistical significance, in the proportion between sex. Lima and Barone [8], in a study on total hip arthroplasty, found out a total frequency of $15.1 \%$ of hospital infections, $6.5 \%$ of superficial wound infection, $6.5 \%$ of deep infection and $2.1 \%$ of urinary tract infection. Pruzansky et al. [14] evaluated risk factors for infection, showing that the most common risks are obesity, anemia, malnutrition and diabetes, in addition to associating diabetes or obesity with all cases of orthopedic infection, with $89 \%$ of urinary infections and with $72 \%$ of cases of anemia after arthroplasty.

Analyzing the clinical outcome of the patients in this study, only $2.4 \%$ of the patients died. According to Goveia et al [5], hospital mortality accounted for about $7.2 \%$ of the patients. Hebert and Xavier [15] reported a mortality rate of $8 \%$ in the first 35 postoperative days and $20-30 \%$ in the first post-fracture year. The mortality rate is twice as high in men and 4 to 5 times higher in patients over 85 years old, when compared to those between 60 and 64 years old [15]. Memtsoudis and colleagues [10], in their systematic review, stated that most postarthroplasty deaths occur within the first 4-6 days, with less than 5\% occurring on the day of the procedure, and that advanced age, male gender, number of comorbidities, and the presence of complications are an independent risk factors for in-hospital mortality.

The fact that hip fractures occur, more commonly, in women, is already well known in the literature. According to Goveia et al., [5] the great majority of patients submitted to hip arthroplasty had a femoral neck fracture, and in addition to being elderly, $60 \%$ were women. This fact can be explained by the higher prevalence of osteoporosis, common in menopausal women. Women are not only more likely to have osteoporosis, but they also present the disease more severely; However, women who take estrogen hormone therapy are 15\% less likely to knee and hip arthroplasty than those who do not.

The literature presents conflicting data regarding the prevalence of anemia in the postoperative period of total hip arthroplasty, mainly due to the definitions of anemia and the conducts established in different services. It is known that bleeding, during total hip arthroplasty, can reach up to $1500 \mathrm{ml}$ [16], and may be greater in the revision of arthroplasty; Which indicates that, following this type of procedure, is common to hemoglobin get lower levels. The prevalence of anemia after total hip arthroplasty ranges from $87 \%+-10 \%$. According to Spahn [17], pre-and postoperative anemia is associated with an increase in hospitalization time, incidence of urinary and respiratory infection, and increased mortality. Mahadevan et al., [18] in turn, found that, among the patients undergoing revision of total hip arthroplasty, blood loss was significantly higher among men, older patients and which surgery was used cement; However, with no significant difference between the percentage of transfused and the number of transfusions, among sex. On the other hand, the need for transfusion is greater in patients who had less pre-operative hemoglobin concentration [18].

Urinary tract infections were also significantly more prevalent in females. Adult women are 50 times more likely to get UTIs than men, and $30 \%$ of women have symptomatic UTIs throughout their lives. Since the main route of urinary tract contamination occurs ascending, this is attributed to the lower anatomical extension of the female urethra and the greater proximity between the vagina and the anus, characteristic of the female genitalia. On the other hand, the incidence of UTI increases among men over 50 years and is associated with urinary instrumentation, including bladder catheterization, and the occurrence of prostatic disease. Pinto et al. [10] showed a prevalence of infection in total hip arthroplasties of $2.8 \%$, most of them women.

The alterations of the genitourinary apparatus involved, in the majority, bladder retention, which was decisive in the male sex. According to Bjerregaard et al., [19] the incidence of post-arthroplasty urinary retention was $40 \%$, and their risk was increased when using spinal anesthesia, without relevant influence with age, gender and type of arthroplasty. The application of spinal anesthesia is a risk factor for urinary retention, increasing the postoperative catheterization by about $50 \%$ when compared to general anesthesia [19]. On the other hand, Griesdale et al., [20] in their cohort study on urinary retention after hip and knee arthroplasty, demonstrated the incidence of $43.3 \%$ of urinary retention in the first 24 hours postoperatively, assuming that being men that underwent hip arthroplasty and used morphine as associated risk factors; The risk of urinary retention among men was $60.4 \%$, compared with $28.5 \%$ among women; And, compared to general anesthesia, men who perform spinal anesthesia with morphine have a 7.1 up to 12.2 times greater chance of urinary retention [20].

The relevance of the study is correlated with the greater knowledge about the clinical and epidemiological profile of patients submitted to total hip arthroplasty; It can rehearse the attention to the previous comorbidities and the associated risks and, consequently, seek adequacy to their behaviors to prevent the occurrence or severity of the complications. The major disadvantage of this study is its retrospective approach, which through an electronic medical record device may have made it possible to lose important patient data, the surgical and postoperative procedures. In addition, this was a study conducted in a private hospital, which greatly favors pathways of conduct and surgical attire, which makes it essential to others with other hospitals and medical routines from other countries.

\section{Conclusion}

Patients submitted to hip arthroplasty, in the present study, were elderly, female, with arterial hypertension, in whom, most of the procedures resulted from osteoarthrosis or hip fracture. The most prevalent complications were anemia, alterations of the genitourinary system, cardiovascular alterations and alterations of the digestive apparatus. Regarding the indication of total hip arthroplasty, the prevalence of women in the occurrence of hip fracture was shown to be more significant; While complications such as anemia and urinary tract infection occurred more prevalently in women, as opposed to genitourinary changes that occurred more commonly in men.

\section{References}

1. Piano L, Golmia R, Scheinberg M (2010) Artroplastia total de quadril e joelho: aspectosclínicosnafaseperioperatória. Einstein 8: 350-353.

2. Nantel J, Termoz N, Vendittoli PA, Lavigne M, Prince F (2009) Gait patterns after total hip arthroplasty and surface replacement arthroplasty. Arch Phys Med Rehabil 90: 463-469. [Crossref]

3. Mobasheri R, Gidwani S, Rosson Jw (2006) The effect of total hip replacement on the employment status of patients under the age of 60 years. Ann R Coll Surg Engl 88: 131-133. [Crossref]

4. Harkess JW (1996)Artroplastia do quadril. In: Crenshaw AH, organizador, Cirurgiaortopédica de Campbell. São Paulo: Manole. 
5. Goveia RG, Mendoza IYQ, Couto GM, Ferreira JAG, Paiva EB, et al. (2015)Perfil dos pacientessubmetidos à artroplastia do quadrilem hospital de ensino. Rev Col Bras Cir 42: 106-110.

6. Yoon PW, Lee YK, Ahn J, Jang EJ, Kim Y, et al. (2014) Epidemiology of hip replacements in Korea from 2007 to 2011. J Korean Med Sci 29: 852-858.[Crossref]

7. Carbone L, Buzkova P, Fink HA, Lee JS, Chen Z, et al (2010) Hip fractures and heart failure: findings from the cardiovascular health study. Eur Heart J 31: 77-84. [Crossref]

8. Lima A, Barone A (2001)Infecçõeshospitalaresem 46 pacientessubmetidos a artroplastia total de quadril. Acta Ortop Bras 9.

9. Piano L, Golmia R, Scheinberg M (2010)Artroplastia total de quadril e joelho: aspectosclínicosnafaseperioperatória. Einstein 8:350-353.

10. Memtsoudis S, Pumberger M, Ma Y, Chiu Y, Fritsch G, et al. (2012) Epidemiology and risk factors for perioperative mortality after total hip and knee arthroplasty. $J$ Orthop Res 30: 1811-21.[Crossref]

11. Banks E, Reeves GK, BeralV, Balkwill A, Liu B, et al. (2009) Hip fracture incidence in relation to age, menopausal status, and age at menopause: prospective analysis. PLoS Med 6: 1-9.[Crossref]

12. Abbas K, Murtaza G, Umer M, Rashid H, Qadir I (2012) Complications of Total Hip Replacement. Journal of the College of Physicians and Surgeons Pakistan 22: 575-578.
13. Dorman T, Adamczyk E, Sunder M, Sibinski M (2008) Elective total hip arthroplasty for patients 75 years of age and older. Chir Narzadow Ruchu Ortop Pol 73: 163-166. [Crossref]

14. Pruzansky J, Bronson M, Grelsamer R, Strauss E, Moucha C (2014) Prevalence of modifiable surgical site infection risk factors in hip and knee joint arthroplasty patients ata $\mathrm{n}$ urban academic hospital. J Arthroplasty 29:272-276.[Crossref]

15. Hebert S, Xavier R (2003)Ortopedia e Traumatologia: princípios e prática. São Paulo: Artmed.

16. Zhang Y, Jordan JM (2010) Epidemiology of osteoarthritis. Clin Geriatr Med 26: 355369.[Crossref]

17. Spahn DR (2010) Anemia and patient blood management in hip and knee surgery: a systematic review of the literature. Anesthesiology 113: 482-495.[Crossref]

18. Mahadavan D, Challand C, Keenan J (2010) Revision total hip replacement: predictors of blood loss, transfusion requirements, and length of hospitalization. $J$ OrthopTraumatol 11: 159-65. [Crossref]

19. Bjerregaard LS, Bogø S, Raaschou S, Troldborg C, Hornum U, et al. (2015) Incidence of and risk factors for postoperative urinary retention in fast-track hip and knee arthroplasty. Acta Orthop 86: 183-188.[Crossref]

20. Griesdale DE, Neufeld J, Dhillon D, Joo J, Sandhu S, et al. (2011) Risk factors for urinary retention after hip or knee replacement: a cohort study. Can J Anaesth 58 1097-1104.[Crossref]

Copyright: (C2017 Wolfovitch LA. This is an open-access article distributed under the terms of the Creative Commons Attribution License, which permits unrestricted use, distribution, and reproduction in any medium, provided the original author and source are credited. 